\title{
Power Density Improvement of Piezoelectric Energy Harvesters via a Novel Hybridization Scheme with Electromagnetic Transduction
}

\author{
Zhongjie Li ${ }^{1,2}\left(\mathbb{0}\right.$, Chuanfu Xin ${ }^{1}$, Yan Peng ${ }^{1,3, *}$, Min Wang ${ }^{1,3, *} \mathbb{C}$, Jun Luo ${ }^{1,3}$, Shaorong Xie ${ }^{1,3}$ and Huayan Pu ${ }^{1,3}$ \\ 1 School of Mechatronic Engineering and Automation, Shanghai University, Shanghai 200444, China; \\ lizhongjie@shu.edu.cn (Z.L.); xcfshu@shu.edu.cn (C.X.); luojun@shu.edu.cn (J.L.); \\ srxie@shu.edu.cn (S.X.); phygood_2001@shu.edu.cn (H.P.) \\ 2 Shanghai Institute of Intelligent Science and Technology, Tongii University, Shanghai 200092, China \\ 3 Engineering Research Center of Unmanned Intelligent Marine Equipment, Ministry of Education, \\ 99 Shangda Rd., Shanghai 200444, China \\ * Correspondence: pengyan@shu.edu.cn (Y.P.); xmwangmin@shu.edu.cn (M.W.)
}

check for

updates

Citation: Li, Z.; Xin, C.; Peng, Y.; Wang, M.; Luo, J.; Xie, S.; Pu, H. Power Density Improvement of Piezoelectric Energy Harvesters via a Novel Hybridization Scheme with Electromagnetic Transduction. Micromachines 2021, 12, 803. https:// doi.org/10.3390/mi12070803

Academic Editors: Qiongfeng Shi and Huicong Liu

Received: 18 May 2021

Accepted: 29 June 2021

Published: 7 July 2021

Publisher's Note: MDPI stays neutral with regard to jurisdictional claims in published maps and institutional affiliations.

Copyright: (C) 2021 by the authors. Licensee MDPI, Basel, Switzerland. This article is an open access article distributed under the terms and conditions of the Creative Commons Attribution (CC BY) license (https:/ / creativecommons.org/licenses/by/ $4.0 /)$.

\begin{abstract}
A novel hybridization scheme is proposed with electromagnetic transduction to improve the power density of piezoelectric energy harvester $(\mathrm{PEH})$ in this paper. Based on the basic cantilever piezoelectric energy harvester (BC-PEH) composed of a mass block, a piezoelectric patch, and a cantilever beam, we replaced the mass block by a magnet array and added a coil array to form the hybrid energy harvester. To enhance the output power of the electromagnetic energy harvester (EMEH), we utilized an alternating magnet array. Then, to compare the power density of the hybrid harvester and $\mathrm{BC}-\mathrm{PEH}$, the experiments of output power were conducted. According to the experimental results, the power densities of the hybrid harvester and BC-PEH are, respectively, $3.53 \mathrm{~mW} / \mathrm{cm}^{3}$ and $5.14 \mu \mathrm{W} / \mathrm{cm}^{3}$ under the conditions of $18.6 \mathrm{~Hz}$ and $0.3 \mathrm{~g}$. Therefore, the power density of the hybrid harvester is 686 times as high as that of the BC-PEH, which verified the power density improvement of PEH via a hybridization scheme with EMEH. Additionally, the hybrid harvester exhibits better performance for charging capacitors, such as charging a $2.2 \mathrm{mF}$ capacitor to $8 \mathrm{~V}$ within $17 \mathrm{~s}$. It is of great significance to further develop self-powered devices.
\end{abstract}

Keywords: piezoelectric; electromagnetic; hybrid energy harvester; power density improvement

\section{Introduction}

The extensive use of smart sensor devices (such as marine environment monitoring wireless sensors, wildfire detectors, etc.), which are usually powered by batteries, leads to a large amount of power consumption. However, due to the limited lifespan of batteries, it severely restricts the continuous operation of smart sensor devices and replacing batteries regularly can cause high costs. To solve these problems, developing self-powered devices by using some approaches to harvest ambient energy, for instance, solar energy [1-3], wind [4-6], tidal energy [7], thermal energy [8,9], mechanical vibration [10,11], and pyroelectric energy $[12,13]$, is a feasible program. The commonly used energy harvesting mechanism is piezoelectric [14-17].

The piezoelectric energy conversion mechanism has been used to extract kinetic energy because of the high power density, simple operation mechanism, and design flexibility [18]. The basic configuration of $\mathrm{PEH}$ is composed of a mass block, a piezoelectric patch, and a cantilever beam. Based on the basic configuration, many novel designs were proposed. Zhang et al. [19] designed a multi-impact harvester with superior performance to extract energy under the low-frequency vibration. Iman et al. [20] collected energy from human motion by using a harvester and powered electronic devices. Based on impact vibration, a low-frequency $\mathrm{PEH}$, assembled with two rigid generating beams and a compliant driving beam, was presented by $\mathrm{Gu}$, which can achieve an average power of $1.53 \mathrm{~mW}$ under the 
conditions of $20.1 \mathrm{~Hz}$ and $0.4 \mathrm{~g}$ [21]. Besides, some original designs of PEHs were proposed, including a cantilever PEH with a revolute joint [22], a press-button type PEH [23], a PEH with a sandwich structure [24], a T-shaped PEH with internal resonance [25], a trussbased compressive-mode PEH [26], a PEH based on the piezoelectric stack [27,28], and a U-shaped bi-directional PEH [29].

Recently, piezoelectric-electromagnetic hybrid harvesters have attracted gravitational attention [30]. Iqbal et al. [31] presented a hybrid harvester, which contains the PEH and $\mathrm{EMEH}$, to collect low-frequency vibration energy from walking motion. The harvester can generate the power of $51 \mu \mathrm{W}$ and $36 \mu \mathrm{W}$ from EMEH and PEH, respectively. Iqbal et al. [32] designed a multimodal hybrid bridge harvester. The power of $2214.32 \mu \mathrm{W}$ and $155.7 \mu \mathrm{W}$ were, respectively, generated from its electromagnetic and piezoelectric portions. Edwards et al. [33] introduced a novel low-frequency vibration energy harvester and conducted a series of simulations and experiments. Based on the experimental results, the harvester can, respectively, achieve the average power of $46.2 \mu \mathrm{W}$ and $3.6 \mu \mathrm{W}$ from electromagnetic and piezoelectric transducers at $5 \mathrm{~Hz}$. Pyo et al. [34] investigated a hybrid harvester by using frequency up-conversion, which can extract energy from an extremely low-frequency mechanical motion and generate peak power of $6.03 \mathrm{~mW}$ and $1.35 \mathrm{~mW}$ from electromagnetic and piezoelectric portions, respectively.

In the above work, researchers mostly use a magnet or a simple combination of several magnets to form the hybrid energy harvester, which can result in small output power of EMEHs. Additionally, Li et al. [35] have proven that an alternating magnet array, which can cause abrupt magnetic flux density changes, can improve the output power of EMEHs. Therefore, we proposed a novel hybrid scheme with an alternating magnet array to improve the power density of PEHs.

In this paper, we presented a hybrid harvester based on the BC-PEH, which displayed excellent performance under the weak excitation. The key contributions include: first, designing a novel hybrid scheme to improve the power density of BC-PEH; second, implementing a simulation to testify the abrupt magnetic flux density (MFD) changes caused by an alternating magnet array; third, conducting experiments of open-circuit voltage, frequency sweep, output power, and charging capacitors to compare the output performance of the hybrid harvester and the BC-PEH; and finally, further demonstrating the high power density of the hybrid harvester by charging millifarad level capacitors.

\section{Configuration and Simulation}

Based on the BC-PEH composed of a mass block, a piezoelectric patch, and a cantilever beam, we replaced the mass block by a magnet array and added a coil array to form the hybrid energy harvester (PEH source and EMEH source). Due to the magnetic damping, the deformation of the piezoelectric material becomes small, so the output power of the PEH decreases. However, the EMEH generates power in the reciprocating motion of the magnet array. Therefore, to compare the total output power of the hybrid harvester and the BC-PEH, we made a prototype and conducted experiments of open-circuit voltage, frequency sweep, output power, and charging capacitors.

The configuration of the hybrid harvester was illustrated in Figure 1a. It is composed of a base, a cantilever beam, a coil bracket, and a magnet frame. In Figure 1a, one end of the cantilever beam and the coil bracket are fixed to the base, and the magnet frame is connected with the other end of the cantilever beam. As shown in Figure 1b, the magnet array contains two magnets, which are installed in the magnet frame, and a proof mass is constituted of the magnet array and magnet frame. As shown in Figure 1c, the coil array placed on either side of the magnet array, including four coils, is mounted in the coil bracket. An electromagnetic energy conversion mechanism is constructed by the coil array and proof mass. Additionally, a piezoelectric patch (as shown in Figure 1a) acts as a piezoelectric energy conversion mechanism with the cantilever beam and proof mass. 


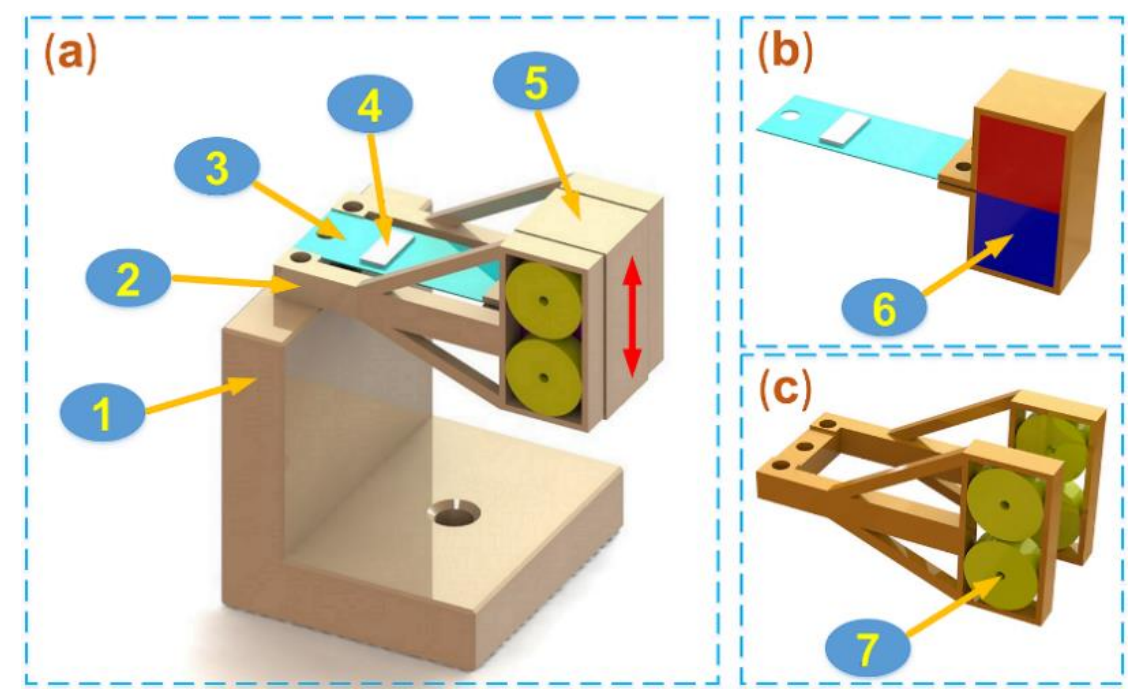

Figure 1. The configuration of the hybrid harvester. The components are, respectively: 1-base; 2-coil bracket; 3-cantilever beam; 4-piezoelectric patch; 5-magnet frame; 6-magnet; and 7-coil. (a) The configuration. (b) The magnet array. (c) The coil array.

When the hybrid harvester is applied excitations, the proof mass is forced to reciprocate in the indicated direction in Figure 1a, which causes the cantilever beam to bend. Then, the bending induces the piezoelectric patch to deform and leads to strain generation inside the material. Therefore, it yields the voltage according to the direct piezoelectric effect. At the same time, relative movement occurs between the proof mass and the coil array. Therefore, the coils generate an induced electromotive force $\left(E_{m f}\right)$, which can be gauged by using Equation (1).

$$
E_{m f}=-N \frac{d(B S)}{d(t)}
$$

where, $N, B, S$, and $t$ are the turns of the coil array, the MFD, the area of the coil, and the time, respectively. In the reciprocating motion of the proof mass, the cantilever beam firstly goes from the initial position to the point of maximum upward displacement, then starts moving down, then reaches the position of maximum downward displacement, and then returns to the initial position. As shown in Figure 2a,c, the cantilever beam is at the initial position and does not deform, so the output voltage of the PEH is zero, which is found in Figure 2e (P1 and P3). However, the proof mass gets the largest movement speed at this moment, so the maximum instantaneous voltage is obtained from the EMEH according to Equation (1), as shown in Figure $2 f(E 1$ and E3). Figure 2b,d show the cantilever beam is at the positions of maximum upward displacement and maximum downward displacement. At this time, the piezoelectric patch achieves the maximum deformation, so the PEH yields the maximum output voltage, as shown in Figure 2e (P2 and P4). Besides, the movement speed of the proof mass is zero, so the EMEH does not generate the output voltage, as shown in Figure $2 \mathrm{f}$ (E2 and E4). 


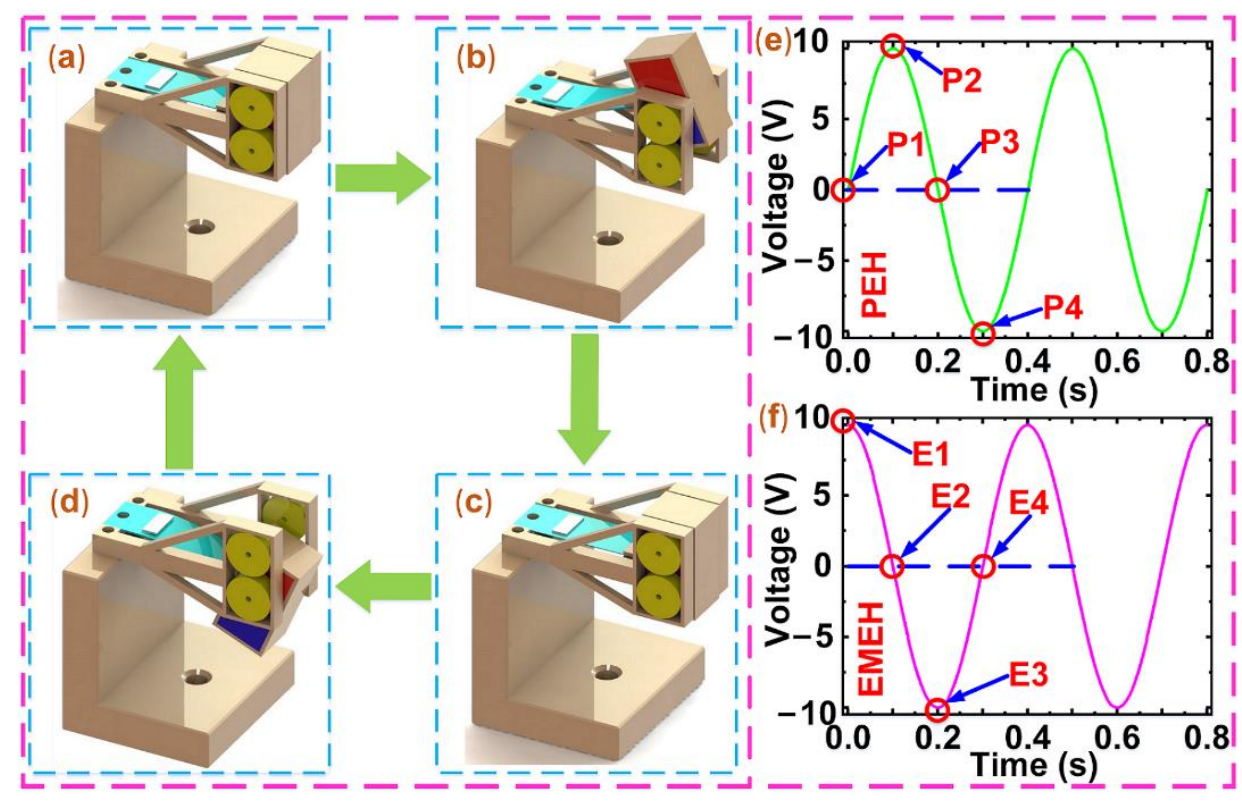

Figure 2. The positions of the cantilever beam in the reciprocating motion of the proof mass. (a) The initial position. (b) The position of maximum upward displacement. (c) The initial position. (d) The position of maximum downward displacement. (e) The simulated voltage of the PEH. (f) The simulated voltage of the EMEH.

According to Equation (1), we can enhance the output voltages of EMEHs by increasing the change rate of the MFD. Moreover, the alternating magnet array can cause abrupt magnetic flux density changes. Therefore, we utilize the way of alternating arrangement of magnetic poles in the scheme. According to the model shown in Figure 3a, the simulation was conducted to demonstrate this phenomenon mentioned above by using COMSOL Multiphysics 5.4 (Sweden). First, based on Figure 3a, we constructed two cube magnets with a length of $12 \mathrm{~mm}$ in COMSOL. The magnetic flux (1 T) directions of the two magnets are opposite along the Z-axis of the coordinate system. Then, the MFD distribution was depicted in the $\mathrm{Z}$ direction of the model. Figure $3 \mathrm{~b}$ displays a step change in MFD between two continuous magnets. Namely, the MFD immediately decreases from the peak value to the minimal value, which verifies the phenomenon above. Moreover, the maximum value of the MFD is on the polar surface of magnets, so the distance between coils and magnets should be as small as possible.

(a)

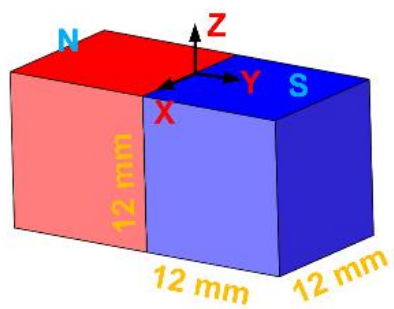

(b)

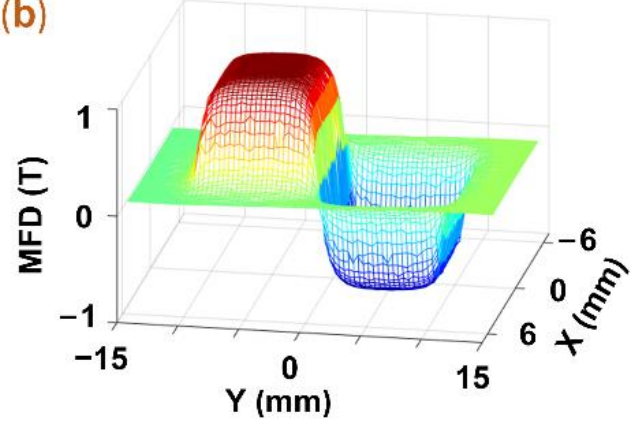

Figure 3. The simulation of the MFD. (a) the simulation model; (b) the MFD distribution in the Z direction of the model.

\section{Experiment and Discussion}

3.1. Prototype Fabrication and Experiment Setup

According to the configuration in Figure 1a, a prototype was fabricated and the exper- 
iments of open-circuit voltage, frequency sweep, output power, and charging capacitors were conducted to examine the output performance of the prototype and compare the outputs with/without the hybridization scheme. The prototype and experiment conditions are shown in Figure 4. The coil bracket and one end of the cantilever beam were fixed to the base with screws, and the magnet frame was joined to the other end of the cantilever beam with screws and nuts. The base, cantilever beam, coil bracket, and magnet frame of the hybrid energy harvester were all made of copper. Furthermore, the distance between the coil and the magnet was set to $0.5 \mathrm{~mm}$.
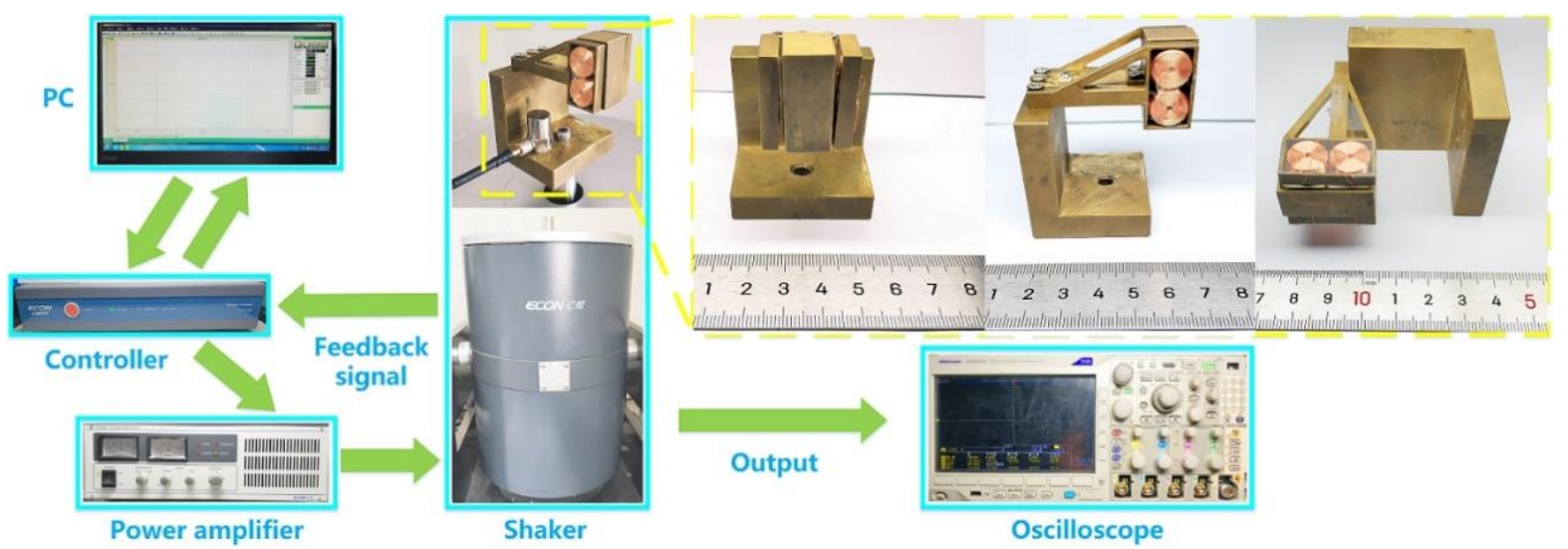

Figure 4. The prototype and experiment conditions.

The types of the shaker, accelerometer, controller, power amplifier, and oscilloscope, which were used in the experiment, are Econ E-JZK-50, Econ EA-YD-181, Econ VT-9002, Econ E5874A (ECON, Kunshan, China) and Tektronix mdo3024 (Tektronix, OK, USA), respectively. The prototype was fixed on the shaker with a screw, and the accelerometer was fixed on the base by using tape. Then, the relevant parameters were set on the PC, and the experiments of open-circuit voltage, frequency sweep, output power, and charging capacitors were conducted. The control signal was generated by the controller after receiving the instructions from the PC. When the power amplifier got the control signal from the controller, the shaker was driven. Then, the feedback signal was transmitted to the controller by the accelerometer, so the hybrid energy harvester works under a constant acceleration. The output voltages of the hybrid energy harvester were all measured by a digital oscilloscope. The detailed material properties and geometric parameters of the prototype are shown in Table 1.

Table 1. Material properties and the geometric parameters of the prototype.

\begin{tabular}{ccc}
\hline Description & & Value \\
\hline Prototype & Dimensions $\left(\mathrm{mm}^{3}\right)$ & $49 \times 23 \times 26$ \\
Cantilever beam & Dimensions $\left(\mathrm{mm}^{3}\right)$ & $35 \times 12 \times 0.5$ \\
Magnet array & Number & 1 \\
& Number of magnets & 2 \\
Magnet & Dimensions $\left(\mathrm{mm}^{3}\right)$ & $12 \times 12 \times 12$ \\
& Magnet grade & N552 \\
Coil array & Material & NdFeB \\
& Number & 2 \\
& Number of coils & 4 \\
Coil & Outside dimension $\left(\mathrm{mm}^{3}\right)$ & $12 \times 4.7$ \\
& Inside dimension $\left(\mathrm{mm}^{3}\right)$ & 1860 \\
& Number of turns & 85.3 \\
& Resistance $(\Omega)$ & 0.1 \\
\hline
\end{tabular}


Table 1. Cont.

\begin{tabular}{ccc}
\hline Description & Value \\
\hline \multirow{2}{*}{ Piezoelectric patch } & Piezoelectric material & PZT-5H \\
& Dimensions $\left(\mathrm{mm}^{3}\right)$ & $7.5 \times 3.5 \times 0.5$ \\
\hline
\end{tabular}

\subsection{Experiments of Open-Circuit Voltage}

The open-circuit voltages of the hybrid energy harvester (PEH source and EMEH source) were measured under the harmonic excitation of different frequencies $(14.6 \mathrm{~Hz}$, $16.6 \mathrm{~Hz}, 18.6 \mathrm{~Hz}, 20.6 \mathrm{~Hz}$, and $22.6 \mathrm{~Hz})$ and constant acceleration $(0.3 \mathrm{~g})$. The open-circuit voltages of the PEH and EMEH are shown in Figure 5a,b.
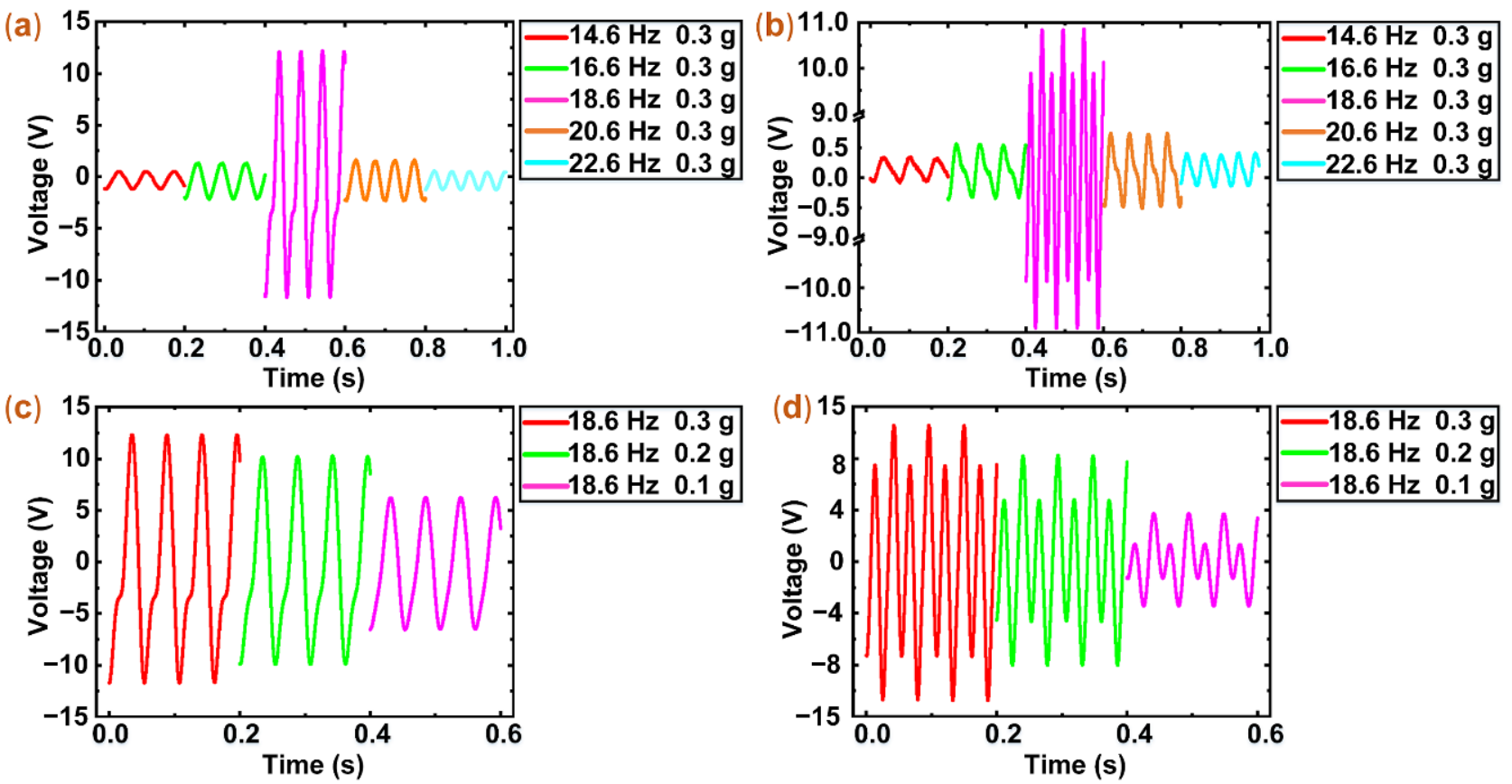

Figure 5. The output voltages of the PEH and EMEH under different frequencies and acceleration. (a,b) The output voltages of the PEH and EMEH under different frequencies $(14.6 \mathrm{~Hz}, 16.6 \mathrm{~Hz}, 18.6 \mathrm{~Hz}, 20.6 \mathrm{~Hz}$, and 22.6 Hz) and constant acceleration $(0.3 \mathrm{~g}) .(\mathbf{c}, \mathbf{d})$ The output voltages of the PEH and EMEH under constant frequency $(18.6 \mathrm{~Hz})$ and different acceleration $(0.1 \mathrm{~g}$, $0.2 \mathrm{~g}$, and $0.3 \mathrm{~g}$ ).

In Figure 5a, a peak-to-peak open-circuit voltage of the PEH is $2.0 \mathrm{~V}$ under the excitation frequency of $14.6 \mathrm{~Hz}$. The voltage increases with the rise of excitation frequency and reaches a maximum of $25.3 \mathrm{~V}$ at $18.6 \mathrm{~Hz}$. Then, the voltage decreases with the increase of excitation frequency and the voltage is $1.9 \mathrm{~V}$ at $22.6 \mathrm{~Hz}$. As shown in Figure 5b, the voltage change of the EMEH is similar to that of the PEH. The voltage is $0.58 \mathrm{~V}$ at $14.6 \mathrm{~Hz}$. As the excitation frequency increases to $18.6 \mathrm{~Hz}$, the voltage reaches a peak of $21.9 \mathrm{~V}$. Then, when the excitation frequency is $22.6 \mathrm{~Hz}$, the voltage decreases to $0.74 \mathrm{~V}$.

The voltage changes of the PEH and EMEH are the same behavior pattern. From 14.6 $\mathrm{Hz}$ to $18.6 \mathrm{~Hz}$, the voltage continually increases. The voltage changes of the frequencies from $14.6 \mathrm{~Hz}$ to $16.6 \mathrm{~Hz}$ are less obvious than that of the frequencies from $16.6 \mathrm{~Hz}$ to $18.6 \mathrm{~Hz}$. From $18.6 \mathrm{~Hz}$ to $22.6 \mathrm{~Hz}$, the voltages unremittingly decrease. The voltage changes of the frequencies from $18.6 \mathrm{~Hz}$ to $20.6 \mathrm{~Hz}$ are more observable than that of the frequencies from $20.6 \mathrm{~Hz}$ to $22.6 \mathrm{~Hz}$. When the excitation frequency increases to near the resonant frequency, the maximum deformation of the piezoelectric patch and the peak rate of magnetic flux density change is achieved. Therefore, the voltages of the PEH and EMEH display an obvious change. 
To further study open-circuit voltages of the PEH and EMEH, we measured the voltages of the PEH and EMEH under constant frequency $(18.6 \mathrm{~Hz})$ and different excitation acceleration $(0.1 \mathrm{~g}, 0.2 \mathrm{~g}, 0.3 \mathrm{~g})$. In Figure $5 \mathrm{c}$, the voltage of the $\mathrm{PEH}$ is $13.01 \mathrm{~V}$ at $0.1 \mathrm{~g}$. As the excitation acceleration rises, the voltage increases. When the excitation acceleration is $0.2 \mathrm{~g}$ and $0.3 \mathrm{~g}$, the voltages are $20.65 \mathrm{~V}$ and $25.73 \mathrm{~V}$, respectively. As shown in Figure $5 \mathrm{~d}$, the voltage trend of the EMEH and the PEH is similar. When the excitation acceleration is $0.1 \mathrm{~g}, 0.2 \mathrm{~g}$, and $0.3 \mathrm{~g}$, the voltages are $7.34 \mathrm{~V}, 16.47 \mathrm{~V}$, and $21.97 \mathrm{~V}$, respectively.

In Figure 5, the open-circuit voltage waveform of the PEH and EMEH is not a standard harmonic. They, respectively, show resembling sawtooth waves and alternating sine waves of different amplitude in the resonant region. At resonance, the deformation of the cantilever beam is large and non-linear, which results in the strain of the piezoelectric patch and the displacement change of the magnet array being non-linear. Therefore, the voltage waveform of the PEH and EMEH displays a nonstandard sine waveform.

\subsection{Experiments of Frequency Sweep}

Afterward, to compare the output voltages of the BC-PEH and the hybrid harvester, the frequency-sweep experiments were conducted. In these experiments, the sweep rate and frequency domain are $0.1 \mathrm{~Hz} / \mathrm{s}$ and $(15 \mathrm{~Hz}, 23 \mathrm{~Hz})$, respectively. Based on the different acceleration $(0.1 \mathrm{~g}, 0.2 \mathrm{~g}$, and $0.3 \mathrm{~g})$, the open-circuit voltages of the BC-PEH and hybrid harvester (PEH source and EMEH source) were measured. The experimental results are shown in Figure 6.
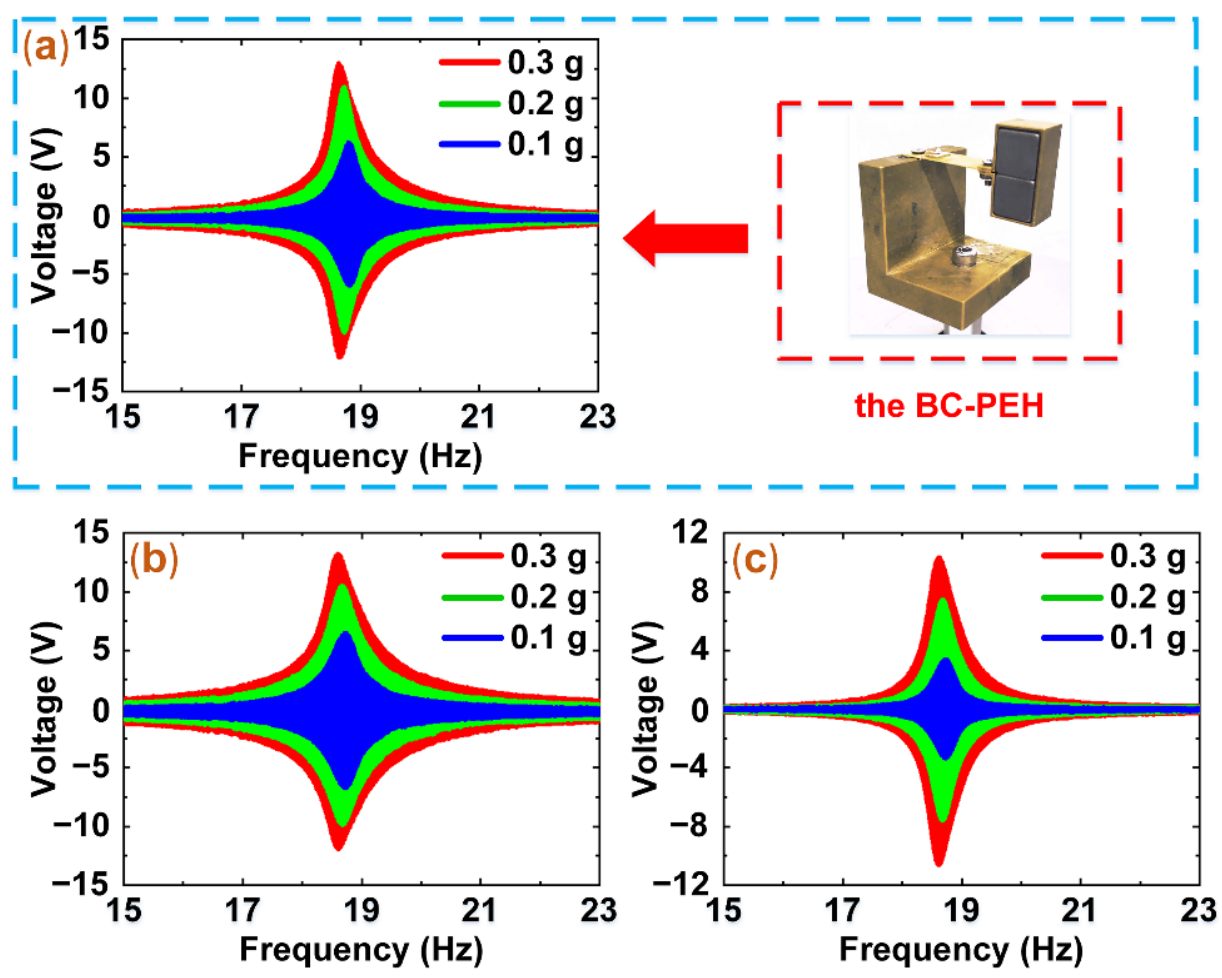

Figure 6. The output voltages of the BC-PEH and the hybrid harvester under different acceleration $(0.1 \mathrm{~g}, 0.2 \mathrm{~g}$, and $0.3 \mathrm{~g})$. (a) The output voltages of the BC-PEH. (b) The output voltages of the PEH. (c) The output voltages of the EMEH.

Figure $6 \mathrm{a}-\mathrm{c}$ display the resonant frequency $(18.6 \mathrm{~Hz})$ of the prototype. The voltages of the BC-PEH and hybrid harvester vary as the excitation acceleration increases and reach a maximum at $18.6 \mathrm{~Hz}$. The voltages of the $\mathrm{PEH}$ are $25.7 \mathrm{~V}, 20.6 \mathrm{~V}$, and $13.1 \mathrm{~V}$ under the resonant frequency and acceleration of $0.3 \mathrm{~g}, 0.2 \mathrm{~g}$, and $0.1 \mathrm{~g}$, respectively. The behavior patterns of the voltage changes of the BC-PEH and EMEH are similar to that of the PEH. The voltages of the BC-PEH are $25.2 \mathrm{~V}, 21.1 \mathrm{~V}$, and $12.3 \mathrm{~V}$ under the acceleration of $0.3 \mathrm{~g}$, 
$0.2 \mathrm{~g}$, and $0.1 \mathrm{~g}$, respectively. Similarly, the voltage changes of $21.9 \mathrm{~V}, 16.5 \mathrm{~V}$, and $7.4 \mathrm{~V}$ for EMEH are obtained under the acceleration of $0.3 \mathrm{~g}, 0.2 \mathrm{~g}$, and $0.1 \mathrm{~g}$, respectively.

In the sweep experiments, the current value of the EMEH is approximately 0 , so the damping of the BC-PEH and hybrid harvester mainly comes from the mechanical damping. Therefore, as shown in Figure 6a,b, the voltage values of the BC-PEH and PEH are nearly the same.

\subsection{Experiments of Output Power}

To compare the output performance of the BC-PEH and hybrid harvester, the output power experiments were carried out under the conditions of $0.3 \mathrm{~g}$ and $18.6 \mathrm{~Hz}$. In these experiments, we recorded the power, voltages, and currents of the BC-PEH and hybrid harvester (PEH source and EMEH source). The results are shown in Figure 7.
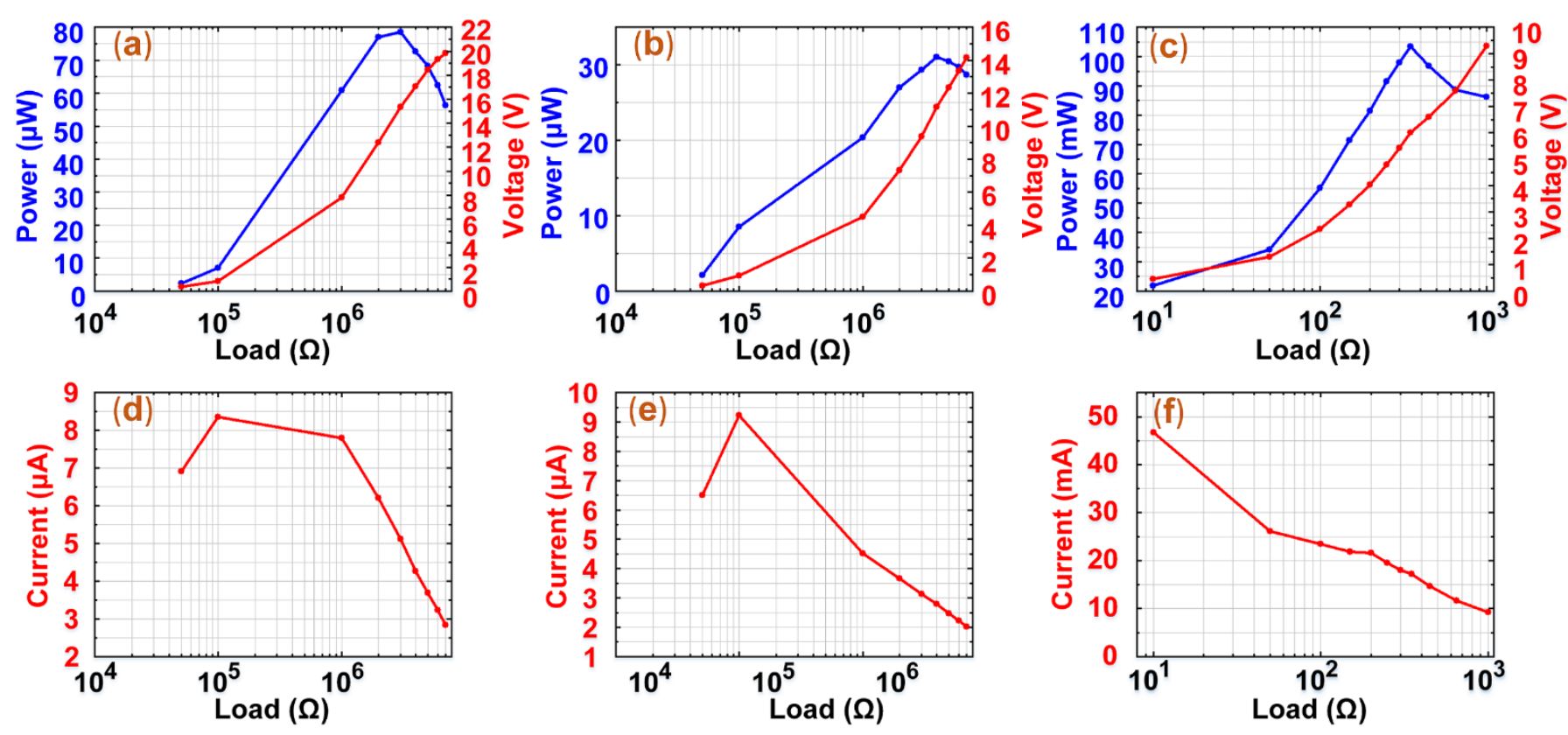

Figure 7. The output power, voltages, and currents of the BC-PEH and hybrid harvester. (a-c) The peak-to-peak output power and voltages of the BC-PEH, PEH, and EMEH. (d-f) The peak-to-peak output currents of the BC-PEH, PEH, and EMEH.

Figure $7 \mathrm{~b}$,e show the changes in the power, voltages, and currents of the PEH under different external electric resistances. The power of the PEH gradually increases and reaches a maximum of $31.08 \mu \mathrm{W}$ and then decreases. The voltages of the PEH continue to enlarge until it approaches the open-circuit voltage as the external electric resistances increase. In addition, the currents of the PEH slightly rise and then continuously decline. Figure $7 \mathrm{a}, \mathrm{c}, \mathrm{d}, \mathrm{f}$ show the changes of the power, voltages, and currents of the BC-PEH and EMEH, which are similar to that of the PEH. The maximum power of the BC-PEH and EMEH is $78.5 \mu \mathrm{W}$ and $103.5 \mathrm{~mW}$, respectively. Compared to the power density of $5.14 \mu \mathrm{W} / \mathrm{cm}^{3}$ of the BC-PEH, the power density of $3.53 \mathrm{~mW} / \mathrm{cm}^{3}$ of the hybrid harvester is 686 times as high as the $\mathrm{BC}-\mathrm{PEH}$. Besides, it should be mentioned that the peak power of the BC-PEH is higher than the PEH, which is attributed to the electromagnetic damping.

To further explore the ability of the hybrid harvester as a power source to supply power to an external load, the average power $\left(P_{\text {avg }}\right)$ of the hybrid harvester was calculated. The voltage waveform of the BC-PEH and hybrid harvester is a nonstandard sine waveform, so we use Equation (2) to obtain the average power of the BC-PEH and hybrid harvester. The average power of the hybrid harvester is approximately $7.98 \mathrm{~mW}$ and the BC-PEH is 
$4.38 \mu \mathrm{W}$. Therefore, the average power of the hybrid harvester is 1821 times as high as the BC-PEH.

$$
P_{\text {avg }}=\int_{0}^{t} U^{2}(t) / R_{m} d t / T
$$

where $U(t), R_{m}, P_{a v g}$, and $T$ are the instantaneous voltage, matching impedance, average power, and full-time of an excitation, respectively.

In Table 2, we displayed a performance comparison for the proposed prototype and other hybrid harvesters with different configurations.

Table 2. The performance comparison of hybrid harvesters.

\begin{tabular}{|c|c|c|c|c|c|}
\hline Ref. & $\begin{array}{l}\text { Dimensions } \\
\left(\mathrm{cm}^{3}\right)\end{array}$ & $\begin{array}{l}\text { Frequency } \\
(\mathrm{Hz})\end{array}$ & $\begin{array}{c}\text { Excitation } \\
\text { (Speed or Acceleration) }\end{array}$ & $\begin{array}{l}\text { Power } \\
(\mathrm{mW})\end{array}$ & $\begin{array}{c}\text { Power Density } \\
\left(\mathrm{mW} / \mathrm{cm}^{3}\right)\end{array}$ \\
\hline [36] & $105 \times 30 \times 20$ & 17 & $0.4 \mathrm{~g}$ & 15.82 & 0.251 \\
\hline [37] & $3.85 \times 3.4 \times 3.7$ & / & $4-6 \mathrm{~km} / \mathrm{h}$ & 0.55 & $1.14 \times 10^{-3}$ \\
\hline [38] & 46.8 & 51 & $0.5 \mathrm{~g}$ & 1.67 & 0.036 \\
\hline [39] & 1.84 & 2 & I & 0.0298 & 0.01619 \\
\hline$[40]$ & 5 & 23.3 & $0.4 \mathrm{~g}$ & 2.26 & 0.452 \\
\hline [41] & $10 \times 4 \times 0.1$ & 33.5 & $0.3 \mathrm{~g}$ & 3.32 & 0.83 \\
\hline [42] & $4 \times 1.5 \times 4$ & 113.5 & $0.6 \mathrm{~g}$ & 3.54 & 0.1475 \\
\hline [43] & 19.2 & 5.2 & $2 \mathrm{~g}$ & 1.2288 & 0.064 \\
\hline [44] & $4 \times 4 \times 1$ & / & $1 \mathrm{~m} / \mathrm{s}$ & 14.0135 & 0.876 \\
\hline [45] & $6 \times 0.7 \times 2$ & 16.8 & $0.5 \mathrm{~g}$ & 3.12 & 0.371 \\
\hline This paper & $4.9 \times 2.3 \times 2.6$ & 18.6 & $0.3 \mathrm{~g}$ & 103.51 & 3.53 \\
\hline
\end{tabular}

The power density of the prototype can reach $3.53 \mathrm{~mW} / \mathrm{cm}^{3}$ under a weak acceleration $(0.3 \mathrm{~g})$ in this paper, which is 14 times, 7 times, and 4 times as high as Refs [34,38,42]. Therefore, the output performance of the prototype in this paper is superior.

\subsection{Experiments of Charging Capacitors}

To further compare the output power of the BC-PEH and hybrid harvester, we conducted charging experiments. We firstly designed an experimental circuit, which contains two harvesters and rectifiers, as shown in Figure 8a. Since the open-circuit voltage magnitudes of the PEH and EMEH are at the same level, we chose to connect the PEH and EMEH in parallel. Two rectifiers were, respectively, connected to the ends of the PEH and EMEH and converted the negative current signals of the $\mathrm{PEH}$ and EMEH into positive ones.

In the charging experiments, we selected six capacitors: $470 \mu \mathrm{F}, 2.2 \mathrm{mF}, 3.3 \mathrm{mF}, 4.7 \mathrm{mF}$, $6.8 \mathrm{mF}$, and $10 \mathrm{mF}$, and set the experimental conditions as follows: a constant acceleration of $0.3 \mathrm{~g}$, a constant frequency of $18.6 \mathrm{~Hz}$. We used the BC-PEH and the hybrid harvester to conduct comparative charging experiments. Before experiments, we fully discharged the capacitors. For the capacitor of $470 \mu \mathrm{F}$, it was only charged to $1.95 \mathrm{~V}$ within $120 \mathrm{~s}$ by using the $\mathrm{BC}-\mathrm{PEH}$, as shown in Figure $8 \mathrm{~d}$. When we used the hybrid harvester to charge the capacitors of $2.2 \mathrm{mF}, 3.3 \mathrm{mF}, 4.7 \mathrm{mF}, 6.8 \mathrm{mF}$, and $10 \mathrm{mF}$, they were, respectively, charged to $8 \mathrm{~V}, 7.2 \mathrm{~V}, 6.3 \mathrm{~V}, 4.9 \mathrm{~V}$, and $4.1 \mathrm{~V}$ within $17 \mathrm{~s}$, as shown in Figure 8c. Compared to the $\mathrm{BC}-\mathrm{PEH}$, the hybrid harvester can charge a larger capacitor to a higher voltage in a shorter period. The hybrid harvester exhibits excellent charge performance.

It should be mentioned that the average power $\left(P_{a}\right)$ for charging capacitors can be calculated by Equation (3):

$$
P_{a}=C_{p}\left(U_{2}^{2}-U_{1}^{2}\right) / 2 \Delta t
$$

where $P_{a}, C_{P}, U_{1}, U_{2}$ and $\Delta t$ represent the average charging power, capacity, initial voltage, final voltage, and charging time, respectively. To compare the power of the BC-PEH and 
the hybrid harvester, we made a histogram of the power, as shown in Figure $8 \mathrm{~b}$. When the capacitor of $10 \mathrm{mF}$ was charged, the power of the hybrid harvester reached $4.94 \mathrm{~mW}$. Compared to the power of $0.0147 \mathrm{~mW}$ for charging the capacitor of $470 \mu \mathrm{F}$ by using the $\mathrm{BC}-\mathrm{PEH}$, the average charging power of the hybrid harvester is 336 times higher than that of the BC-PEH. In addition, to store more energy at the same time, it is necessary to choose a capacitor with a large capacity.

(a)
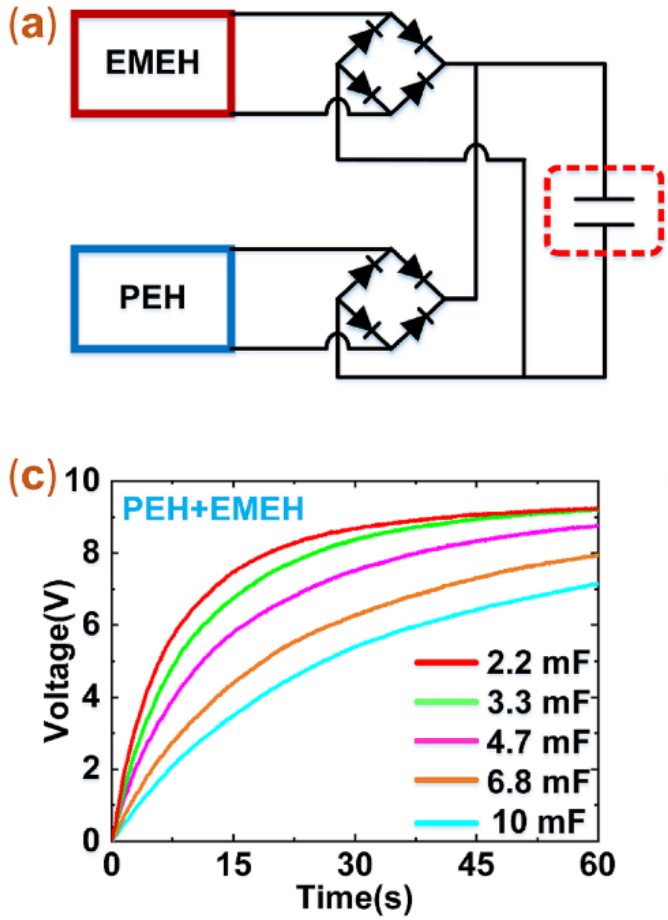
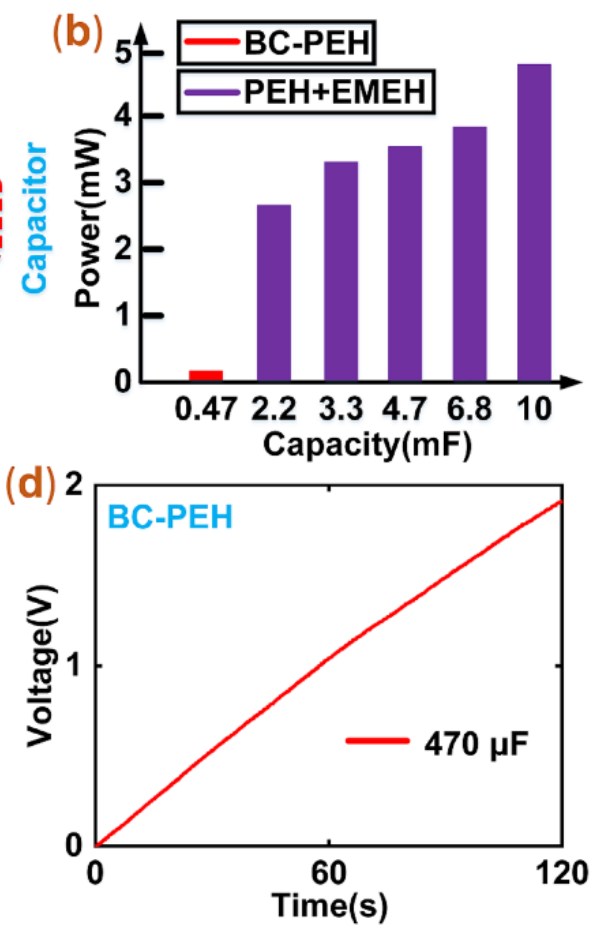

Figure 8. The experimental circuit and results of charging capacitors. (a) The circuit of charging capacitors. (b) The histogram of the average charging power. (c) The results of charging capacitors by using the hybrid harvester. (d) The result of charging capacitor by using the BC-PEH.

\section{Conclusions}

This paper proposed a novel hybridization scheme with electromagnetic transduction to enhance the power density of PEHs. The hybrid energy harvester was designed based on the BC-PEH. To compare the power density of the BC-PEH and the hybrid energy harvester, we built a prototype and conducted experiments of open-circuit voltage, frequency sweep, output power, and charging capacitors. According to the experimental results, the key conclusions of this paper are as follows:

1. The EMEH can yield a high voltage of $21.9 \mathrm{~V}$ under a weak acceleration of $0.3 \mathrm{~g}$ by using an alternating magnet array, which can result in abrupt magnetic flux density changes.

2. Comparing the peak power of the BC-PEH and hybrid harvester, the output power $(103.53 \mathrm{~mW})$ of the hybrid harvester is 1318 times as high as the output power $(78.5 \mu \mathrm{W})$ of the BC-PEH.

3. Comparing the power densities and average power of the BC-PEH and hybrid harvester, the power density and average power of the hybrid harvester are, respectively, 686 times and 1821 times higher than that of the BC-PEH.

4. The hybrid harvester also displays excellent charging performance because of the high output power. According to the experimental results, the average charging power of the hybrid harvester is 336 times higher than that of the BC-PEH.

The hybrid energy harvester shows a better energy capture performance, which verifies that the power density improvement of PEHs can use a hybridization scheme with 
electromagnetic transduction and also displays its great potential to successfully power low-power electronic components.

Author Contributions: Z.L. conceived the idea and conducted the experiments. C.X. wrote the original draft. Z.L. and M.W. reviewed and revised the paper. Y.P. provided financial support. J.L. and S.X. helped fabricated the prototype. H.P. helped with data processing. All authors have read and agreed to the published version of the manuscript.

Funding: This work was funded and supported by National Natural Science Foundation of China (No.: 61773254; No.: 62001281) and Shanghai Sailing Program (No.: 20YF1412700).

Institutional Review Board Statement: Not applicable.

Informed Consent Statement: Not applicable.

Data Availability Statement: The data supporting the findings of this paper is available from the corresponding authors on request.

Conflicts of Interest: The authors declare no conflict of interest.

\section{References}

1. Guo, C.X.; Guai, G.H.; Li, C.M. Graphene Based Materials: Enhancing Solar Energy Harvesting. Adv. Energy Mater. 2011, 1, 448-452. [CrossRef]

2. $\quad$ Lin, G.-J.; Wang, H.-P.; Lien, D.-H.; Fu, P.-H.; Chang, H.-C.; Ho, C.-H.; Lin, C.-A.; Lai, K.-Y.; He, J.-H. A broadband and omnidirectional light-harvesting scheme employing nanospheres on Si solar cells. Nano Energy 2014, 6, 36-43. [CrossRef]

3. Ma, W.; Li, X.; Lu, H.; Zhang, M.; Yang, X.; Zhang, T.; Wu, L.; Cao, G.; Song, W. A flexible self-charged power panel for harvesting and storing solar and mechanical energy. Nano Energy 2019, 65, 104082. [CrossRef]

4. Wu, N.; Wang, Q.; Xie, X. Wind energy harvesting with a piezoelectric harvester. Smart Mater. Struct. 2013, 22, 095023. [CrossRef]

5. Orrego, S.; Shoele, K.; Ruas, A.; Doran, K.; Caggiano, B.; Mittal, R.; Kang, S.H. Harvesting ambient wind energy with an inverted piezoelectric flag. Appl. Energy 2017, 194, 212-222. [CrossRef]

6. Nabavi, S.; Zhang, L. Portable Wind Energy Harvesters for Low-Power Applications: A Survey. Sensors 2016, 16, 1101. [CrossRef]

7. Bryden, I.; Grinsted, T.; Melville, G. Assessing the potential of a simple channel to deliver useful energy. Appl. Ocean Res. 2004, 26, 198-204. [CrossRef]

8. Wang, Q.; Bowen, C.R.; Lewis, R.; Chen, J.; Lei, W.; Zhang, H.; Li, M.-Y.; Jiang, S. Hexagonal boron nitride nanosheets doped pyroelectric ceramic composite for high-performance thermal energy harvesting. Nano Energy 2019, 60, 144-152. [CrossRef]

9. Kishore, R.; Priya, S.J. A Review on Low-Grade Thermal Energy Harvesting: Materials, Methods and Devices. Materials 2018, 11, 1433. [CrossRef] [PubMed]

10. Wei, C.; Jing, X. A comprehensive review on vibration energy harvesting: Modelling and realization. Renew. Sustain. Energy Rev. 2017, 74, 1-18. [CrossRef]

11. Won, S.S.; Seo, H.; Kawahara, M.; Glinsek, S.; Lee, J.; Kim, Y.; Jeong, C.K.; Kingon, A.I.; Kim, S.-H. Flexible vibrational energy harvesting devices using strain-engineered perovskite piezoelectric thin films. Nano Energy 2019, 55, 182-192. [CrossRef]

12. Battista, L.; Mecozzi, L.; Coppola, S.; Vespini, V.; Grilli, S.; Ferraro, P. Graphene and carbon black nano-composite polymer absorbers for a pyro-electric solar energy harvesting device based on $\mathrm{LiNbO}_{3}$ crystals. Appl. Energy 2014, 136, 357-362. [CrossRef]

13. Kang, M.; Yeatman, E.M. Coupling of piezo- and pyro-electric effects in miniature thermal energy harvesters. Appl. Energy 2020, 262, 114496. [CrossRef]

14. Fan, K.; Chang, J.; Pedrycz, W.; Liu, Z.; Zhu, Y. A nonlinear piezoelectric energy harvester for various mechanical motions. Appl. Phys. Lett. 2015, 106, 223902. [CrossRef]

15. Cao, J.; Wang, W.; Zhou, S.; Inman, D.; Lin, J. Nonlinear time-varying potential bistable energy harvesting from human motion. Appl. Phys. Lett. 2015, 107. [CrossRef]

16. Kuang, Y.; Zhu, M. Characterisation of a knee-joint energy harvester powering a wireless communication sensing node. Smart Mater. Struct. 2016, 25, 055013. [CrossRef]

17. Fan, K.; Liu, Z.; Liu, H.; Wang, L.; Zhu, Y.; Yu, B. Scavenging energy from human walking through a shoe-mounted piezoelectric harvester. Appl. Phys. Lett. 2017, 110, 143902. [CrossRef]

18. Wu, N.; Bao, B.; Wang, Q. Review on engineering structural designs for efficient piezoelectric energy harvesting to obtain high power output. Eng. Struct. 2021, 235, 112068. [CrossRef]

19. Zhang, Y.; Cai, C.; Zhang, W. Experimental study of a multi-impact energy harvester under low frequency excitations. Smart Mater. Struct. 2014, 23, 055002. [CrossRef]

20. Izadgoshasb, I.; Lim, Y.Y.; Lake, N.; Tang, L.; Padilla, R.V.; Kashiwao, T. Optimizing orientation of piezoelectric cantilever beam for harvesting energy from human walking. Energy Convers. Manag. 2018, 161, 66-73. [CrossRef]

21. Gu, L. Low-frequency piezoelectric energy harvesting prototype suitable for the MEMS implementation. Microelectron. J. 2011, 42, 277-282. [CrossRef] 
22. Li, Z.; Naguib, H.E. Effect of revolute joint mechanism on the performance of cantilever piezoelectric energy harvester. Smart Mater. Struct. 2019, 28, 085043. [CrossRef]

23. Yang, C.; Chen, K.; Chen, C. Model and Characterization of a Press-Button-Type Piezoelectric Energy Harvester. IEEE/ASME Trans. Mechatron. 2019, 24, 132-143. [CrossRef]

24. Li, X.; Upadrashta, D.; Yu, K.; Yang, Y. Sandwich piezoelectric energy harvester: Analytical modeling and experimental validation. Energy Convers. Manag. 2018, 176, 69-85. [CrossRef]

25. Xie, Z.; Wang, T.; Kwuimy, C.K.; Shao, Y.; Huang, W. Design, analysis and experimental study of a T-shaped piezoelectric energy harvester with internal resonance. Smart Mater. Struct. 2019, 28, 085027. [CrossRef]

26. Li, Z.; Yang, Z.; Naguib, H.; Zu, J. Design and Studies on a Low-Frequency Truss-Based Compressive-Mode Piezoelectric Energy Harvester. IEEE/ASME Trans. Mechatron. 2018, 23, 2849-2858. [CrossRef]

27. Peng, Y.; Xu, Z.; Wang, M.; Li, Z.; Peng, J.; Luo, J.; Xie, S.; Pu, H.; Yang, Z. Investigation of frequency-up conversion effect on the performance improvement of stack-based piezoelectric generators. Renew. Energy 2021, 172, 551-563. [CrossRef]

28. Wang, M.; Yin, P.; Li, Z.; Sun, Y.; Ding, J.; Luo, J.; Xie, S.; Peng, Y.; Pu, H. Harnessing energy from spring suspension systems with a compressive-mode high-power-density piezoelectric transducer. Energy Convers. Manag. 2020, 220, 113050. [CrossRef]

29. Shih, H.-A.; Su, W.-J. Theoretical analysis and experimental study of a nonlinear U-shaped bi-directional piezoelectric energy harvester. Smart Mater. Struct. 2018, 28, 015017. [CrossRef]

30. Li, Z.; Li, T.; Yang, Z.; Naguib, H.E. Toward a $0.33 \mathrm{~W}$ piezoelectric and electromagnetic hybrid energy harvester: Design, experimental studies and self-powered applications. Appl. Energy 2019, 255, 113805. [CrossRef]

31. Iqbal, M.; Nauman, M.M.; Khan, F.U.; Abas, P.E.; Cheok, Q.; Iqbal, A.; Aissa, B. Multimodal Hybrid Piezoelectric-Electromagnetic Insole Energy Harvester Using PVDF Generators. Electronics 2020, 9, 635. [CrossRef]

32. Iqbal, M.; Khan, F.U. Hybrid vibration and wind energy harvesting using combined piezoelectric and electromagnetic conversion for bridge health monitoring applications. Energy Convers. Manag. 2018, 172, 611-618. [CrossRef]

33. Edwards, B.; Aw, K.C.; Hu, A.P.; Tang, L. Hybrid electromagnetic-piezoelectric transduction for a frequency up-converted energy harvester. In Proceedings of the 2015 IEEE International Conference on Advanced Intelligent Mechatronics (AIM), Busan, Korea, 7-11 July 2015; pp. 1149-1154.

34. Pyo, S.; Kwon, D.-S.; Ko, H.-J.; Eun, Y.; Kim, J. Frequency Up-Conversion Hybrid Energy Harvester Combining Piezoelectric and Electromagnetic Transduction Mechanisms. Int. J. Precis. Eng. Manuf. Green Technol. 2021, 1-11. [CrossRef]

35. Li, Z.; Liu, Y.; Yin, P.; Peng, Y.; Luo, J.; Xie, S.; Pu, H. Constituting abrupt magnetic flux density change for power density improvement in electromagnetic energy harvesting. Int. J. Mech. Sci. 2021, 198, 106363. [CrossRef]

36. Toyabur, R.M.; Salauddin, M.; Cho, H.; Park, J.Y. A multimodal hybrid energy harvester based on piezoelectric-electromagnetic mechanisms for low-frequency ambient vibrations. Energy Convers. Manag. 2018, 168, 454-466. [CrossRef]

37. Hamid, R.; Yuce, M.R. A wearable energy harvester unit using piezoelectric-electromagnetic hybrid technique. Sens. Actuators A Phys. 2017, 257, 198-207. [CrossRef]

38. Iqbal, M.; Khan, F.U.; Mehdi, M.; Cheok, Q.; Abas, E.; Nauman, M.M. Power harvesting footwear based on piezo-electromagnetic hybrid generator for sustainable wearable microelectronics. J. King Saud Univ. Eng. Sci. 2020. [CrossRef]

39. Li, Y.; Chen, Z.; Zheng, G.; Zhong, W.; Jiang, L.; Yang, Y.; Jiang, L.; Chen, Y.; Wong, C.-P. A magnetized microneedle-array based flexible triboelectric-electromagnetic hybrid generator for human motion monitoring. Nano Energy 2020, 69, 104415. [CrossRef]

40. Xia, H.; Chen, R.; Ren, L. Analysis of piezoelectric-electromagnetic hybrid vibration energy harvester under different electrical boundary conditions. Sens. Actuators A Phys. 2015, 234, 87-98. [CrossRef]

41. Xia, H.; Chen, R.; Ren, L. Parameter tuning of piezoelectric-electromagnetic hybrid vibration energy harvester by magnetic force: Modeling and experiment. Sens. Actuators A Phys. 2017, 257, 73-83. [CrossRef]

42. Li, P.; Gao, S.; Cai, H.; Wu, L. Theoretical analysis and experimental study for nonlinear hybrid piezoelectric and electromagnetic energy harvester. Microsyst. Technol. 2016, 22, 727-739. [CrossRef]

43. Halim, M.A.; Kabir, M.H.; Cho, H.; Park, J.Y. A Frequency Up-Converted Hybrid Energy Harvester Using Transverse ImpactDriven Piezoelectric Bimorph for Human-Limb Motion. Micromachines 2019, 10, 701. [CrossRef] [PubMed]

44. Beyaz, M.İ.; Tat, F.; Özkaya, K.Y.; Özbek, R. Hybrid Magnetic-Piezoelectric Energy Harvester for Power Generation around Waistline During Gait. J. Electr. Eng. Technol. 2020, 15, 227-233. [CrossRef]

45. Fan, K.; Hao, J.; Tan, Q.; Cai, M. A monostable hybrid energy harvester for capturing energy from low-frequency excitations. J. Intell. Mater. Syst. Struct. 2019, 30, 2716-2732. [CrossRef] 